\title{
Prospects for an activity-based approach to the design and use of VR simulators in vocational training
}

\author{
Tatyana Gavrilova*, and Olga Zhigalova \\ Fast East Federal University, 690922, Vladivostok, Russia
}

\begin{abstract}
The purpose of the article is to analyze the possibilities of the psychological theory of activity as a theoretical basis for the development and effective use of VR simulators in professional training. Based on the review of works on pedagogical theories used in the development of virtual educational applications, as well as on the theory of activity and its application to professional training, the conclusion is made about the undisclosed potential of the activity approach. The most promising position is the position on the functional structure of activity (motive-goal-actionoperation) and the understanding of learning as a system of educational tasks. The development of an activity-based approach to professional education can be the development of a classification of typical educational and professional tasks and scenarios for modeling on virtual simulators. Work in this direction was started by a team of IT specialists, teachers, psychologists and psychophysiologists from the School of Pedagogy of the Far Eastern Federal University.
\end{abstract}

\section{Introduction}

The implementation of educational VR applications in practice can be complicated by the fact that education managers do not have a clear idea of how a particular application relates to existing pedagogical theories and practices. As meta-analytical reviews show [1], [2], [3], [4] most developers of virtual products for education in their methodological justifications so far rarely indicate the pedagogical theories and didactic foundations on which their product is built or for which it can be useful. Developers often act through trial and error, similar to the experience of developing products for the entertainment industry and focusing primarily on technical capabilities and ergonomic characteristics.

The problem is also complicated by the fact that research on the adequacy and effectiveness of virtual educational products is very far behind the rapid development of technologies and the entry into the market of educational services of a huge number of offers. Apparently, this is one of the reasons that virtual reality for education is still at the experimental stage - prototyping and testing with students [3].And, thus, clarification of the theoretical and methodological grounds for the development and application of educational

\footnotetext{
* Corresponding author: tgavrilovaster@gmail.com
} 
VR products can be useful both for potential consumers of these products, and for their developers and distributors.

In the modern world, education is carried out on the basis of various pedagogical approaches that organize the process of knowledge and skills transfer in different ways, focus on different educational effects and different methods of motivation and learning.

According to a recent meta-analysis by Radianti et al. [3] only $32 \%$ of scientific publications on the study of the effectiveness of virtual educational applications for higher education, carried out within the period from 2016 to 2018, contain a reference to specific learning theories, indicate the type of educational activities or target results. At the same time, the theory of experimental learning by Kolb [5], was mentioned most often, in $11 \%$ of the articles. Whereas the rest of the seven other theories mentioned (behavioral learning, learning cone theory, constructivism, gamification theory, contextual learning, Jeffreys simulation theory, generative learning, and operational learning) constitute only $3 \%$ each. The experimental theory of learning was also the most widely used according to the results of other meta-reviews [6], [3].

According to many researchers, the theory of experimental learning, like no other, best meets the opportunities and benefits of learning in a virtual environment.

Kolb [7] and his followers provide training as a four-phase ascending spiral cycle that reproduces the sequence of transition from obtaining direct experience to its reflection, from reflection to the formation of theoretical concepts and then to the verification/implementation of them in practice. Moreover, training can begin with any phase of the cycle. An approximate application scheme of experimental training is as follows: the teacher provides students with the opportunity to get a specific experience such as industrial practice, laboratory experiment or role-playing game, and then organizes personal or group reflections on this experience. The theoretical conceptualization phase focuses on understanding the meaning of the experience, often with the addition of lectures on relevant topics or self-reading materials. Students are then asked to apply what they have learned in their own lives and in some work context. Thus, it is assumed that students simultaneously receive and create information.

Through the use of simulation in a virtual environment, students have the opportunity to obtain the experiences comparable to those in the real world, but in more accessible and less risky forms. At the same time, the organization of practical classes with a virtual simulator according to the Flask scheme significantly improves the learning outcomes: for example, the study of the topic of computer security in a virtual laboratory gives better results if it is organized according to the phases of experimental training, compared with the step-by-step approach [8].

Research [8], [9], [10], [11] show that educational VR applications, mainly, allow to effectively organize two phases of the learning cycle: the phase of obtaining a specific perceptual experience (forming ideas) and the phase of active experimentation (forming understanding). These two phases are well complemented by the reflection phase already outside the virtual environment, with the help of traditional educational materials and activities (reference books, collective discussions, group exercises, etc.).

B. Dalgarno and M. J. W. Lee [12] based on the analysis of research in the 1990s and 2000s, have derived five main features of three-dimensional virtual learning environments:

- "facilitating tasks that lead to an expanded spatial representation of knowledge,

- great opportunities for experimental learning,

- increase of motivation / engagement,

- improving the contextualization of learning and

- richer / more effective collaborative learning" [12, 10].

In other words, virtual learning environments allow students to understand the meaning of concepts and perform practical tasks that are often difficult or impossible to complete in 
the real world. They provide a rich learning context that leads to a higher level of motivation and engagement, as well as provide ample opportunities for collaborative interaction with peers.

Thus, virtual learning environments can significantly increase the activity of students in comparison with the activity of the teacher. In terms of Russian pedagogical psychologythey allow you to fully realize the subjectivity of the student in the process of their training. This superposition of the learner is also fundamental in the constructivist theory of learning.

Constructivism as a philosophical and psychological explanatory principle states that knowledge is not transmitted, but is constructed by the individual in the process of his interaction with the environment [13]. This trend develops as an opposition to behaviorist theories of learning, in which the formation of knowledge is presented as a reproductive process. The theoretical basis of the constructivist approach to learning is the theory of Zh.Piaget and L. S. Vygotsky.

According to Jonassen, knowledge construction can be facilitated in learning environments that allow:

- to provide multiple representations of reality; thereby: avoiding oversimplification of instructions, to present the natural complexity of the real world;

- to display the natural complexity of the real world;

- to focus on constructing knowledge rather than reproducing it;

- to present authentic tasks (contextualization, not abstraction);

- to provide a real learning environment based on specific cases, rather than a pre-defined learning sequence;

- to encourage reflexive practice;

- to create knowledge that depends on the context and content;

- support the joint accumulation of knowledge through social negotiations, rather than competition between students for recognition [14].

And it is the virtual reality environment, according to many scientists, that creates the most favorable conditions for the implementation of the principles of learning based on the ideas of constructivism [15], [16], [17], [18], [11], [19].

Based on the constructivist theory of learning, proposals are also put forward for developers of virtual educational applications. For example, Chen [20] proposed the VRID model, which offers a clear guide to creating an educational virtual environment based on the pedagogical theory of constructivism.

Experimentalism and constructivism emphasize the role of student activity, and thus are very consistent [21] with the activity-based approach to learning developed in Russian psychology and pedagogy, which also originates in the works of L. S. Vygotsky [22] and finds its origin in the works of A. N. Leontiev [23] and C. L. Rubinstein [24] and U. Engestrem [25].

The purpose of this study is to analyze the possibilities of an activity-based approach to learning as a basis for the development and effective use of VR simulators in professional training.

\section{Materials and methods}

The research was conducted on the material of articles that indicated the activity-based approach to learning in the design, development or use of VR applications in the educational process, as well as the works of authoritative representatives of the activitybased approach in psychology and pedagogy [22], [23], [26], [28]. 
The search for articles for the study was carried out on the basis of the Russian Science Citation Index on the platform of the Russian Science Citation Index (the core of the RSCI) and in the database of SinceDirect.

The study used the method of logical and theoretical analysis of the content of activitybased learning concepts in order to identify applied recommendations that are useful for the development of educational VR applications. The method of comparative analysis was also used to study the possibilities of the activity approach in comparison with other learning concepts used as the basis for the development of virtual educational products.

Research questions:

1. In what aspects was the activity theory of learning most often considered in the works related to virtual reality, and the development of virtual simulators, in particular?

2. What provisions of the theory of activity are most promising for the development and application of VR simulators in professional education?

\section{Results}

\subsection{Theory of activity in the works on virtual reality in training}

A search in the Russian Science Citation Index and Since Direct databases for articles with the keywords "activity theory", "virtual reality", "learning" did not find any articles directly related to the subject of this study. If there were any articles, they were related to the application of activity theory, either for use in a wide variety of educational activities, or for use in the development of software for VR.

For example, it is proposed to use activity theory to study and develop the activity of a programmer as a user of visual software [29] or to evaluate the behavior of users in immersive virtual environments [30].

\subsection{The theory of activity as a basis for the development and application of VR applications for professional training}

The psychological theory of activity originated in the works of L. S. Vygotsky [22] and S. L. Rubinstein [24] and was further formulated by A. N. Leontiev [23] and further developed by his followers, both in Russia and in the Scandinavian school of activity Y. Engestrom [25].

In Russia, within the framework of the activity approach, several psychological and pedagogical concepts of learning have been formed: the theory of educational activity, the theory of step-by-step formation of mental actions, psychological and didactic concepts of problem-based learning. In Europe, the ideas of the activity approach were developed in the theory of expansive learning [25]. Each of these concepts develops complementary strategies for implementing an activity-based approach to learning.

The main provisions of the activity approach that can be applied to professional training are:

1. " Relying on the concept of activity allows us to solve the problem of the purpose of education. The purpose of education is to prepare a person for future activity in society, and the content of education is the development of general methods and forms of human activity" [28]. This provision is most consistent with the essence of professional education, which from this point of view should be directed not so much to the development of professional knowledge and skills, but to the development of professional activity as a whole, which is not reduced to the sum of knowledge and skills. Knowledge and skills quickly become obsolete in contrast to the activity as a social function. 
2. From a psychological point of view, activity has a functional structure, which involves the allocation of not individual "elements", but "units" - such components that contain all the basic properties inherent in a holistic activity [22]. The analysis of human behavior according to "unity" in L. S. Vygotsky's cultural-historical theory is contrasted with the element-by-element analysis accepted in behaviorism.

The disadvantage of element-by-element analysis is that the whole is not a sum of elements, but has characteristics that are irreducible to individual components. The main units of activity analysis, according to A. N. Leontiev, are actions and operations [23].

An action is understood as a relatively completed stage of activity - a process aimed at achieving a conscious, predictable result, that is, a goal. An operation is a way to achieve the goal of an action, which is determined by the conditions for performing the action. Activity theory in works on virtual reality in education

3. These individual units of activity relate to the backbone signs such as "motive," "goal" and "the conditions for performing the action."

4. "Motive" in activity theory is considered as the object to which the activity is directed and which, in turn, meets any needs. Learning motivation does not arise before the start of training, but in its process. "Development of the psychological basis of training does not precede the beginning of learning, but is performed in an indissoluble internal connection with it, in the course of its progressive movement" [22, 24].

5. The goal is presented as a predictable immediate result of the action. Goals are given to the individual by objective circumstances, and are not invented and set by him arbitrarily. The goal is tested and filled with pre-met content as the action is completed.

6. The action performed always corresponds to some task. A task is a goal set under certain conditions [23].

In the theory of activity, the educational activity of general education is revealed as a system of educational tasks, which is primarily aimed at the mental development of a student [26]. A learning task differs from all other types of tasks, first of all, in that its goal and result consist in changing the student him student interacts [26].

In professional education, the focus of training is much broader, the content of educational tasks is different, but the educational task itself can also be considered as a component of the educational process. It is the provision on the educational task and the related provision on the functional structure of the activity that seems to be the most promising for the implementation of the activity approach in the development and use of VR simulators in professional education.

\section{Discussion and conclusions}

The studied materials allow us to state the following:

1. The psychological theory of activity has not yet found implementation in the development of VR applications for professional education. Its potential is not yet fully realized by developers and customers.

2. One of the most promising provisions of the theory of activity is the provision on the educational task as a component of educational activity.

In professional education, the educational task is primarily focused on solving practical tasks that affect the scope of future professional activity, which allow you to master labor functions. This allows us to distinguish a special type of educational tasks - educational and professional tasks.

Educational and professional tasks are aimed at understanding professional experience and acquiring the skills to apply knowledge in various professional situations. In the process of solving them, it is necessary to understand the professional situation, correlate it 
with the available opportunities, determine and choose a way out of the professional situation and further transform it.

One of the possibilities of professional training with the help of virtual reality technologies is that it can occur with minimal intervention of the teacher and puts the student in an active rather than passive position. This makes it possible to fully implement both the principles of the constructivist and activity-based approach to learning. But this requires such formats and design of a virtual training application that could fully reflect the entire structure of educational activities (motive-goal-actions-operations) and is aimed at solving a particular type of educational and professional task. The most appropriate format for this is the VR simulator format, which allows you to simulate realistic conditions and scenarios of professional activity and work out individual actions and operations, bringing them to the level of skills and abilities.

To implement productive ideas of activity theory for the design and application of VR simulators for professional training, we offer the following steps:

- to develop a typology of educational and professional tasks for modeling on VR simulators;

- to develop standard scenarios for each type of simulated educational and professional task, taking into account the functional structure of the educational activity (motivegoal-actions-operations);

- to develop a general methodology for organizing training using an "active" VR simulator.

The beginning of such steps was laid at the FEFU School of Pedagogy, where the development of a virtual simulator for teaching students of the pedagogical profession was started. The project is implemented on an interdisciplinary basis by a team of IT specialists, teachers, psychologists and psychophysiologist.

This work was supported by the Ministry of Science and Higher Education of the Russia (State assignment No. 0657-2020-0009)

\section{References}

1. S. Kahai, R. Jestire, H. Rue, British Journal of Educational Technology 44(6), 969-985 (2013). doi:10.1111/bjet.12105.

2. E. Johnston, G. Olivas, P. Steele, Dr.C. Smith, L. Bailey, Journal of Educational Technology Systems 46, (2017). doi: 004723951774556.

3. J. Radianti, T.A. Majchrzak, J. Fromm, I. Wohlgenannt, Computers \& Education 147, 103778 (2020). doi:10.1016/j.compedu.2019.103778

4. D. Hamilton, J. McKechnie, E. Edgerton, J. Comput. Educ. 8, 1-32 (2021). doi:10.1007/s40692-020-00169-2

5. D.A. Kolb, Experiential learning: Experience as the source of learning and development (Englewood Cliffs, NJ, Prentice-Hall, 1984).

6. S.K. Loke, Australasian Journal of Educational Technology 31 (1) (2015). doi:10.14742/ajet.2532

7. A. Kolb, D.A. Kolb, Eight important things to know about the experiential learning cycle. (2018). Corpus ID: 198795437// https://www.semanticscholar.org/paper/Eightimportant-things-to-know-about-the-learning-Kolb-

Kolb/ea1334dfb3ef05f4bbafacdf63f8523f1340a444

8. A. Konak, T.K. Clark, M. Nasereddin, Computers \& Education 72, 11-22 (2014). 
9. C.J. Chen, S.C. Toh, W.M.F.W. Ismail, Journal of research on technology in education 38 (2), 123-141 (2005)doi: 10.1080/15391523.2005.10782453

10. L. Jarmon, T. Traphagan, M. Mayrath, A. Trivedi, Computers \& Education 53 (1), 169-182 (2009) doi: 10.1016/j.compedu.2009.01.010

11. D.R. dela Cruz, D.M.M. Mendoza, 2018 IEEE games, entertainment, media conference (pp. 1-23). IEEE (2018)

12. B. Dalgarno, M.J.W. Lee, British Journal of Educational Technology 41 (1), 10-32 (2010)

13. C.J.: Chen, Themes in Science and Technology Education 2 (1), 71-90 (2009)

14. D.H. Jonassen, Educational Technology 34(4), 34-37 (1994)

15. W. Winn, A conceptual basis for educational applications of virtual reality, Human interface technology laboratory (Washington Technology Center, University of Washington, 1993) http://www.hitl.washington.edu/research/learning_center/winn/winnpaper.html

16. D. Jonassen, S. Land, Theoretical Foundations of Learning Environments (Taylor \& Francis Group, Routledge, 2000).

17. L.F. Gül, A. Williams, N. Gu, Constructivist Learning Theory in Virtual Design Studios. Computational Design Methods and Technologies: Applications in CAD, CAM and CAE Education. 10.4018/978-1-61350-180-1.ch009 (2012)

18. H. Huang, S. Liaw, The International Review of Research in Open and Distributed Learning 19, 91-115 (2018)

19. M. Alizadeh, CALL-EJ 20, 21-30 (2019).

20. C.J. Chen, C.S. Teh, Australasian Journal of Educational Technology 29 (5) doi:10.14742/ajet.247 (2013)

21. D.H. Jonassen, L. Rohrer-Murphy, ETR\&D 47, 61-79 (1999). doi:10.1007/BF02299477

22. L.S. Vygotsky, V. Myshlenieirech', M. Yaroshevsky, (red.) Pedagogika, Moskva 2, 5361, (1984).

23. A.N. Leontyev, Activity. Consciousness. Personality (Politizdat Publ, Moscow, 1975).

24. S.L. Rubinshteyn, Basics of general psychology (Piter Publ., St-Petersburg, 2005).

25. L.P. Vetoshkina, L.N. Goryunova, Engestryoma. Kul'turno-istoricheskaya psihologiya 9 (1), 13-21 (2013)

26. B.D. El'konin, Psihologicheskaya nauka I obrazovanie 25 (4), 28-39 (2020).

27. I.A. Zimnyaya, Innovacionnye proekty I programmy v obrazovanii 6, 3-13 (2009)

28. A.V. Borovskikh, N.Kh. Rozov, Voprosyfilosofii 5, 90-102 (2012).

29. V.L. Averbukh, N.V. Averbukh, P.A. Vasev, I.L. Gvozdarev, G.I. Levchuk, L.O. Melkozerov, Bulletin of the Tomsk Polytechnic University. Geo Assets Engineering 331 (1), 195-210 (2020). doi: 10.18799/24131830/2020/1/2461

30. M. Roussou, O. Martin, M. Mel, Cognition Technology and Work 10, 141-153 (2008). 10.1007/s10111-007-0070-3. 